Literature of Food Investigation" : 7, No. 1, March 1935. Compiled by Agnes Elisabeth Glennis, assisted by Gwen Davies. Pp. $371+$ xiii. (London : H.M. Stationery Office, 1937.) 5s. net); but it is hoped during the next twelve months to bring the "Index" up to date and to complete abstracts of the literature published in 1935 and 1936, which will form No. 2 of vol. 7, and vol. 8. Meanwhile the first number of vol. 9, containing abstracts of papers published during 1937 , is in preparation. The papers noted in the present number are arranged in fifteen sections, and there is an author index extending to twenty pages. The compiler gives a brief review of developments during 1933-34, selecting the following subjects : gas-storage of meat and fruit, storage of rice, eggs, anti-oxidants for fats and oils, and engineering. Attention is directed to the fact that 1934 was the centenary of the invention of the earliest continuous refrigerating machine, by Jacob Perkin, which used ether as refrigerant, and was the first real landmark in the history of modern refrigeration, so far as technique is concerned.

\section{Studies in Ancient Astronomy}

A sMalc collection of papers recently published in Meddelande Från Lunds Astronomiska Observatorium makes an interesting contribution to the study of the early history of astronomy. In an article entitled "Greek Cosmogony and Astronomy", Dr. K. Lundmark briefly traces the development of Greek astronomy from the first indications of some primitive astronomical knowledge found in the Homeric poems and in the work of Hesiod to the great work of the Alexandrine astronomers and mathematicians, culminating in the production of the "Almagest" in the second century A.D. A very useful synopsis for rapid reference is included of Greek astronomers and their contributions to astronomical ideas and observation. In another paper, P. Collinder studies the distribution of the birthplaces of the astronomers of antiquity. He remarks that the Hellenic peninsula itself produced but few in contrast with the west coast of Asia Minor, with Alexandria and the coast of southern Italy. It was, in fact, in the great merchant and shipping towns of these latter localities where the Greeks would best receive the importation of astronomical knowledge from the Babylonians, Egyptians and Phœenicians. A further contribution by $\mathbf{B}$. Svenonius describes his examination of certain rock sculptures found in Ostrogothie, Sweden. These engravings, which may date from the bronze age, include amongst the representations of men, animals, ships and primitive weapons, groupings of small cavities, which it is agreed represent groupings of the bright stars into constellations. M. Svenonius identifies the following constellations: the Great Bear, Cassiopeia, Perseus, Cepheus, Auriga, Orion and Leo. An examination by earlier Swedish investigators of similar rocks found in Bohuslän leads to the same general conclusion that the forms of several easily recognizable constellations were copied by some of the prehistoric watchers of the skies. In a supplementary note, A. Ohlmarks contributes remarks on these rock engravings and their relation to the history of early religious beliefs.

\section{Physics Research at Osaka}

THE volume of Collected Papers for 1936 from the physics section of the Faculty of Science of Osaka University includes 33 papers which have appeared in scientific periodicals between February 1936 and March 1937. The papers are in their covers as issued as reprints and are bound together with wire to constitute the volume, which is $10 \cdot 1$ in. $\times 7 \cdot 4 \mathrm{in} . \times 1$ in. Twenty-two of them are from the Proceedings of the Physico-Mathematical Society of Japan, five are Reports of Radio Research in Japan and two are from the Institute of Physical and Chemical Research, and five other institutions contribute a paper each. The papers from the Physico-Mathematical Society are nearly equally divided between problems of atomic structure and radiation, hydrodynamics and electricity. A table of contents is provided in which each paper is numbered and the number is printed on the right hand top corner of the cover of each so that reference is easy. The various publications from which the papers are reproduced appear to have very nearly the same size of page, slightly larger than that of the volume, except in one instance in which the page is 0.2 inch less wide. This inexpensive form of issuing collected papers seems to be on the increase.

\section{Films for Promoting International Understanding}

IN Film Progress of July, the Central Information Bureau for Educational Films, Ltd., announced the impending release of "Living in Wales", the second of its series of talking films designed to help the peoples of the world to gain a clearer insight into each other's lives and thereby to promote sympathetic mutual understanding. The first of the series, "Living in the Netherlands", is reported to have been well received both at The Hague and in London. "Living in Wales" was used at the Congrès Internationale de l'Enseignement Primaire et de l'Education Populaire to illustrate an address by Dr. G. H. Green of Aberystwyth on "The Cinematograph as a Means of Education for International Understanding". The paper emphasizes the fact that the educational film is not merely an additional means of illustrating or confirming what the teacher conveys through the medium of words, but also provides the closest possible approximation to real first-hand experience. It postulates four essentials for the success of films as instruments for promoting international understanding: an adequate supply of suitable trustworthy films, efficient machinery for production, distribution and publicity, comprehensive experiments and investigations into the technique of education by means of the film, and a centre for acquainting teachers not merely with the films and projectors available but also with all matters relating to films. The same issue of Film Progress announces the decision of Osaka City authorities to build an "Educational Movie Hall" at a cost of 500,000 yen for the benefit of primary school pupils. 